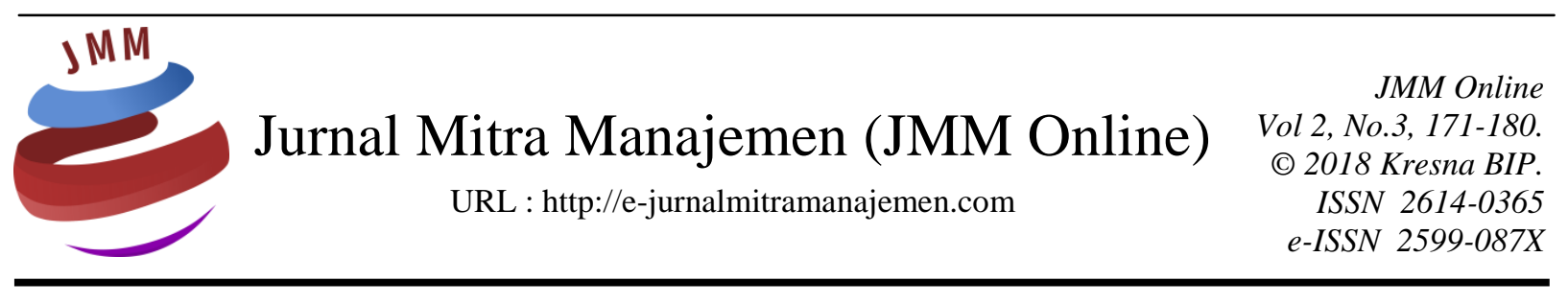

\title{
SISTEM INFORMASI PENJUALAN DAN PEMESANAN DAZZLE STORE BERBASIS WEBSITE
}

\author{
Ovie Nur Khasanah \\ Universitas Muhammadiyah Surakarta
}

INFORMASI ARTIKEL

Dikirim : 16 Mei 2018

Revisi pertama : 17 Mei 2018

Diterima : 18 Mei 2018

Tersedia online : 31 Mei 2018

Kata Kunci : dazzle store, sistem informasi, penjualan, pakaian

Email : ovienurkhasanah4@gmail.com

\section{ABSTRAK}

Dazzle Store salah satu usaha yang bergerak di bidang penjualan pakaian pria yang sudah menggunakan layanan internet sebagai media pemasaran produk. Layanan internet yang dipakai untuk pemasaran atau mempromosikan produk pakaian adalah Instagram dan Facebook. Namun, dalam pencatatan transaksi jual beli masih menggunaka cara yang manual menyebabkan sering kehilangan data penjualan sehingga hasil laporan yang ada menjadi tidak akurat. Ditengah persaingan pasar yang begitu ketat Dazzle Store ingin memberikan pelayanan yang memuaskan dengan selalu menghadirkan inovasi dan kemudahan bagi para konsumen. Untuk itu Dazzle Store membutuhkan sebuah sarana untuk menunjang transaksi penjualan dan media promosi dan efektif. Metode penelitian yang digunakan oleh penulis menggunakan metode waterfall. Proses transaksi jual-beli masih harus dilakukan secara konvesional yaitu konsumen harus datang ke toko dan melakukan transaksi ditempat. Penulis membuat Sistem Informasi Penjualan dan Pemesanan berbasis website yang diharapkan dapat menjadi solusi untuk mengatasi permasalahan yang ada dan mampu meningkatkan penjualan pada Dazzle Store. 


\section{PENDAHULUAN \\ Latar Belakang}

Semakin pesatnya pertumbuhan teknologi saat ini memberikan dampak positif bagi pesaing bisnis, salah satunya dalam bidang penjualan. Dengan adanya teknologi yang dapat digunakan oleh siapapun dan kapanpun menuntut kaum pebisnis agar jeli dalam melihat peluang dan kesempatan dalam meningkatkan kinerja bisnis mereka. Salah satunya yang dilakukan oleh Dazzle Store, bisnis yang bergerak dalam bidang penjualan pakaian pria. Dalam upaya meningkatkan nilai penjualan dan pemasaran saat ini belum sepenuhnya berjalan sesuai dengan target penjualan ataupun pemesanan yang ditetapkan perharinya karena terkendala oleh letak toko yang tidak terlalu dikeramaian kota dan masih kurang gencarnya pemasaran yang dilakukan oleh pihak toko.

Informasi atau pemasaran yang dibuat dalam bentuk spanduk belum sepenuhnya efektif untuk menarik calon pelanggan agar tersedia berkunjung guna melihat atau membeli atau memesan produk pakaian yang ada di store tersebut. Sehingga pihak pemilik Dazzle Store yang sebelumnya bisa memenuhi target dan terkadang sulit untuk mencapai target penjualan penjualan perharinya. Maka melalui sistem informasi yang disajikan dan ditampilkan dalam bentuk website ini diharapkan mampu meningkatkan nilai penjualan dan pemesanan perharinya karena dapat diakses dengan mudah dan dapat dijangkau siapa saja, Dan informasi yang disertakan melalui web disajikan secara lengkap dan update meliputi model pakaian, harga, diskon, koleksi produk terbaru.

Dalam teori akutansi, sistem informasi penjualan adalah sub sistem informasi bisnis yang mencakup kumpulan prosedur yang melasanakan, mencatat, mengkalkulasi, membuat dokumen dan informasi penjualan untuk keperluan manajemen dan bagian lain yang berkepentingan, mulai dari diterimanya order penjualan sampai mencata timbulnya tagihan. (Muhammad, 2013).

Berdasarkan penjelasan diatas, akan merancang sebuah sistem penjualan dan pemesanan berbasis web yang digunakan untuk mempermudah dalam menjalan proses bisnisnya dengan mempermudah melakukan penjualan produk dengan online yang membantu pemasaran produk di Dazzle Store.

\section{Rumusan Masalah}

Berdasarkan latar belakang masalah yang telah diuraikan, maka rumusan masalah yang dibahas ialah "Bagaimana membuat sistem informasi penjualan dan pemesanan Dazzle Store berbasis website ini sebagai media pemasaran dan penjualan produk yang efektif dan efesien melalui website."

\section{Tujuan Penelitian}

Berdasarkan rumusan masalah diatas, maka tujuan penelitian adalah untuk menyediakan website Dazzle Store untuk menyediakan sarana penjualan, pemesanan dan informasi kepada masyarakat luas. 


\section{KAJIAN PUSTAKA}

\section{Sistem informasi}

Sistem didefinisikan sebagai sekumpulan prosedur yang saling berkaitan dan saling terhubung untuk melakukan suatu tugas bersama-sama. Secara garis besar, sebuah sistem informasi terdiri atas tiga komponen utama. Ketiga komponen tersebut mencakup software, hardware dan brainware. (Pratama (2014:7)).

\section{E-Commerce}

E-Commerce mulai muncul ditahun 1990-an melalui adanya inisiatif untuk mengubah paradigma transaksi jual beli dan pembayaran dari cara konversional ke dalam bentuk digital elektronik berbasiskan komputer dan jaringan internet. (Pratama $(2015: 2))$.

\section{Website}

Menurut Yuhefizar (2013) World Wide Web (www) atau website adalah sebuah sistem penyebaran informasi melalui internet.

\section{Blackbox Testing}

Blackbox Testing disebut pengujian di sisi pembangunan dilakukan oleh pengembang / programmer dari aplikasi bersangkutan atau mereka yang mengerti dan terlibat didalam pengembangan sistem tersebut. Pratama (2014:50).

\section{METODE PENELITIAN \\ Waktu dan Tempat Penelitian}

Pelaksanaan penelitian selama 4 bulan dimulai pada bulan Januari 2018 hingga April 2018. Penelitian dilaksanakan di 'Dazzle Store' di Boyolali Jawa Tengah. Peneliti memilih Dazzle Store karena toko tersebut merupakan toko pakaian remaja yang menyediakan berbagai macam jenis pakaian remaja jaman sekarang dan memiliki pelanggan yang cukup banyak.

Dalam perancangan sistem pada tugas akhir ini penulis menggunakan metode Waterfall. Waterfall Process Model merupakan model pengembangan sistem yang sistematik dan sekuensial dimulai pada tingkat dan kemajuan sistem di seluruh tahapan seperti analisis, desain, kode, pengujian dan pemeliharaan. Secara garis besar metode waterfall mempunyai langkah-langkah sebagai berikut :

1. Analisa Kebutuhan

Langkah ini merupakan analisa terhadap kebutuhan sistem. Dalam langkah ini pengumpulan data dilakukan dengan melakukan wawacara. Dengan menggunakan sistem ini maka penulis akan mengenali informasi sebanyak mungkin sehingga tercipta sebuah sistem komputer yang bisa melakukan tugas-tugas sesuai dengan keinginan user. Dalam tahapan ini akan dihasilkan sebuah dokumen yang berisi data kebutuhan user dan akan menjadi acuan untuk membuat sebuah program.

2. Desain sistem

Dalam tahapan ini penulis akan merancang sebuah sistem yang baru dengan menggunakan pemodelan UML (Unified Modelling Language). UML adalah bahasa pemodelan untuk sistem atau perangkat lunak. 


\section{Penulisan Kode Program}

Pada tahap ini penulis akan mencoba untuk melakukan penulisan kode program atau coding menggunakan bahasa pemrogaman PHP (Personal Home Page). Dengan menggunakan bahasa pemrograman PHP maka desain sistem yang telah dirancang akan diterapkan menjadi sebuah aplikasi yang berbasis website.

4. Pengujian Program

Pada tahapan ini penulis menggunakan metode blackbox. Dengan menggunakan metode ini kita tida perlu tahu apa yang sesungguhnya terjadi dalam sistem ini. Kita hanya menguji input dan outputnya, artinya dengan berbagai masukan yang kita berikan, sistem dapat memberikan output sesuai yang kita inginkan.

5. Penerapan Program dan Pemeliharaan

Ini merupakan tahap terakhir dalam model waterfall. Software yang sudah jadi dijalankan serta dilakukan pemeliharaan. Pemeliharaan termasuk dalam memperbaiki kesalahan sebelumnya.

\section{Perancangan Sistem}

\section{Use Case Diagram}

Use Case Diagram adalah deskripsi fungsi dari sebuah sistem dari prespektif pengguna. Pertama, usecase admin dibagi menjadi 5 (lima) aktifitas yang ditunjukan Gambar 1 dibawah ini.

\section{Gambar 1. Use Case Admin}

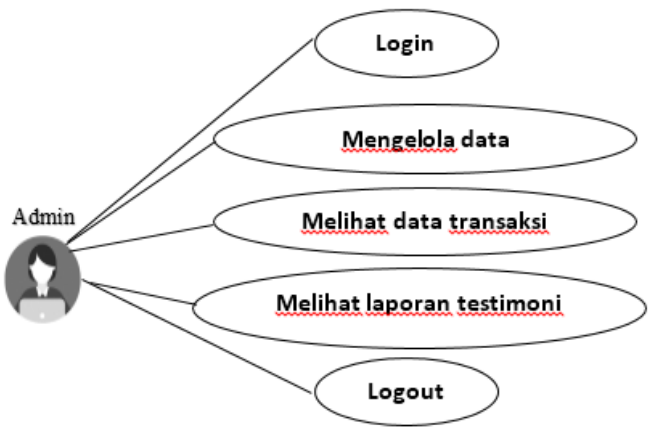

Kedua, use case user member dibagi menjadi 5 (lima) aktivitas yang ditunjukan pada Gambar 2 dibawah ini.

\section{Gambar 2. Use Case User Member}

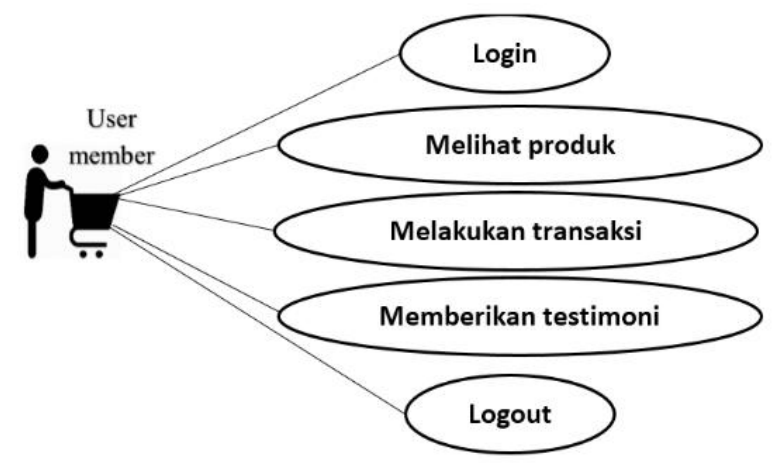


Ketiga, usecase user non-member dibagi menjadi 6 (enam) aktivitas yang ditunjukan pada Gambar 3.

Gambar 3. Use Case User Non-Member

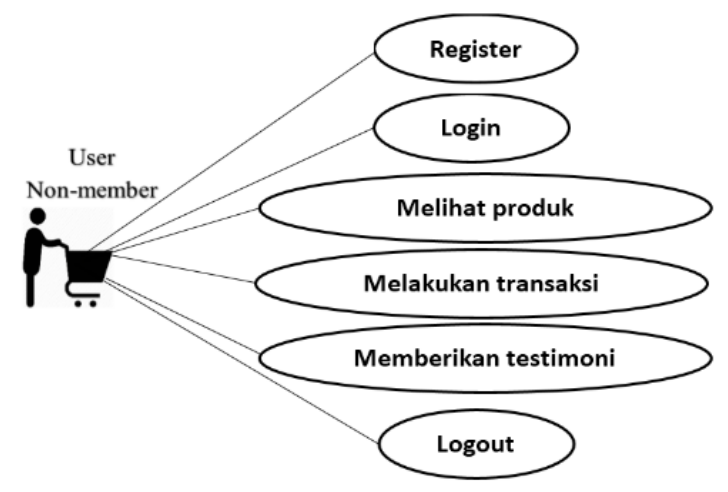

\section{User Interface}

Berikut adalah rancangan user interface yang merupakan gambaran awal bentuk tampilan grafis, yang nantinya akan diimplementasikan dalam sistem yang akan dibuat. Gambar adalah rancangan halaman utama, terdapat menu beranda dan Men's Cloth. Sedangkan gambar adalah rancangan user interface dari halaman admin, yang nantinya terdapat menu dashboard, kelola produk, transaksi, testimoni dan logout.

\section{Gambar 4. User Interface Halaman Utama Untuk User}

\begin{tabular}{|c|c|c|c|}
\hline \multicolumn{3}{|c|}{ DAZZLE CLOTING } \\
\hline Beranda & Men's Cloth \\
\hline \multicolumn{1}{|c|}{ New Produk } \\
\hline Celena & Kaos & Kemeja & Jaket \\
\hline Beli & Beli & Beli & Beli \\
\hline Tas & Sepatu & Jam & Toni \\
\hline Beli & Beli & Beli & Beli \\
\hline
\end{tabular}

Gambar 5. User Interface Halaman Utama untuk Admin

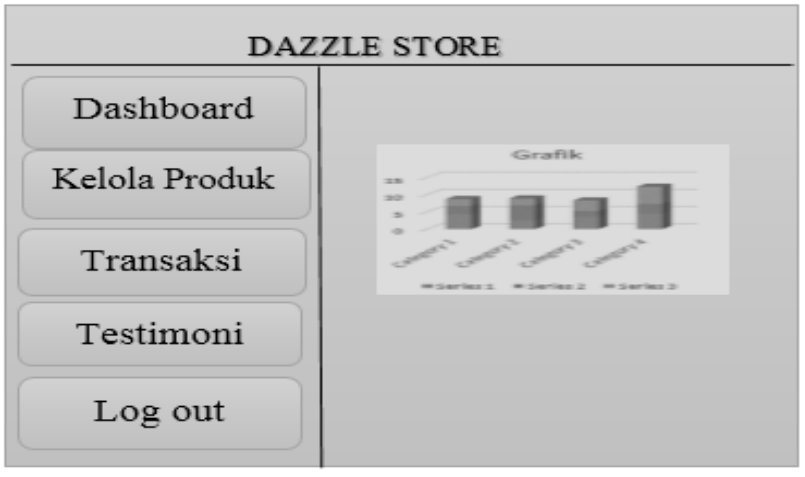




\section{HASIL PENELITIAN DAN PEMBAHASAN \\ Tampilan Sistem \\ Halaman Login}

Pada saat admin membuka sistem untuk mengelola data maka admin wajib memasukan username dan password di halaman login yang bertujuan untuk masuk pada sistem gambar 6 merupakan tampilan halaman login.

\section{Gambar 6. Tampilan Halaman Login}

Silahkan Login

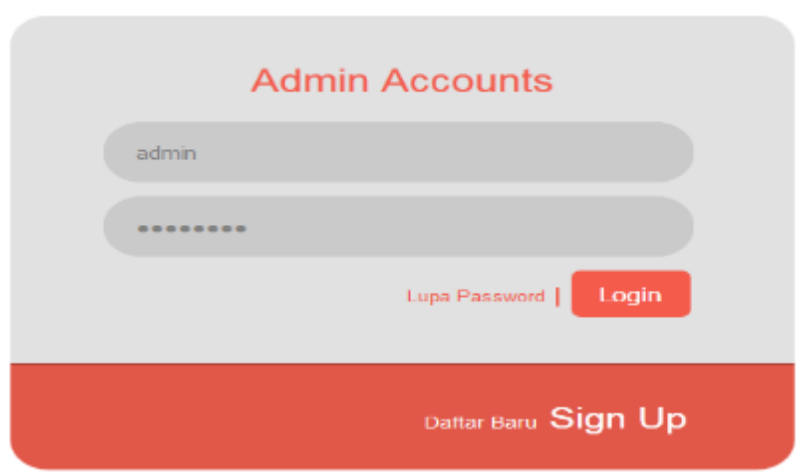

Sumber : Hasil Dokumentasi Website (2018)

\section{Halaman Utama Admin}

Tampilan pada halaman utama untuk admin menampilkan grafik penjualan dazzle store dimenu dashboard. Selain menu dashboard terdapat beberapa menu lainnya yaitu menu slinder, menu produk, menu transaksi, menu testimony dan menu logout. Seperti yang di tunjukkan pada gambar 7.

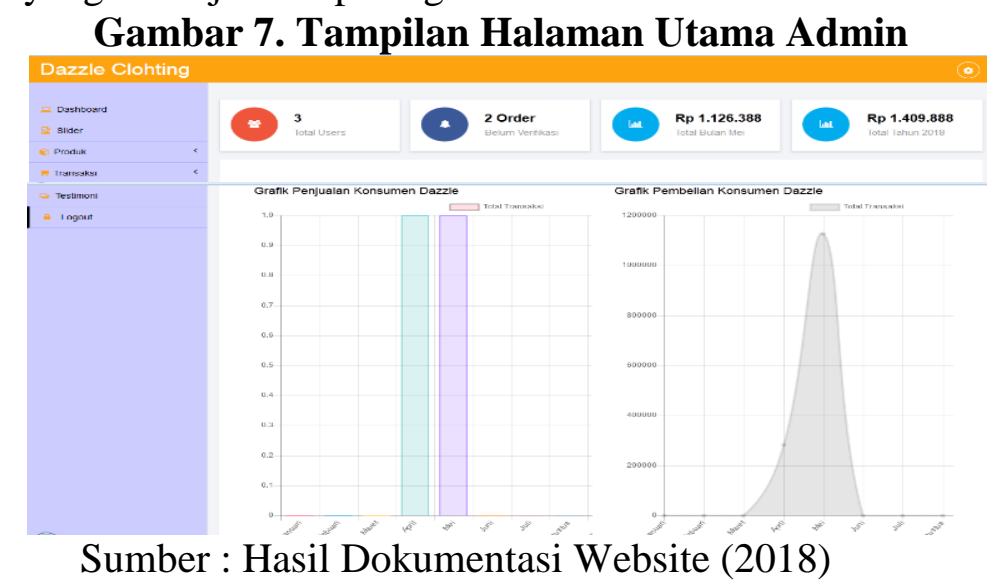

\section{Halaman Utama User}

Tampilan pada halaman utama untuk user menampilkan produk terbaru dari Dazzle Store yang tersedia. Pada menu men's clothing terdapat kategori produk untuk memudahkan customer mencari produk sesuai kategori yang diinginkan. Selain itu terdapat menu Contact yang terdapat kontak yang bisa untuk mengirim pesan ke Dazzle Store. Seperti yang ditunjukkan pada gambar 8. 
Gambar 8. Tampilan Halaman Utama User

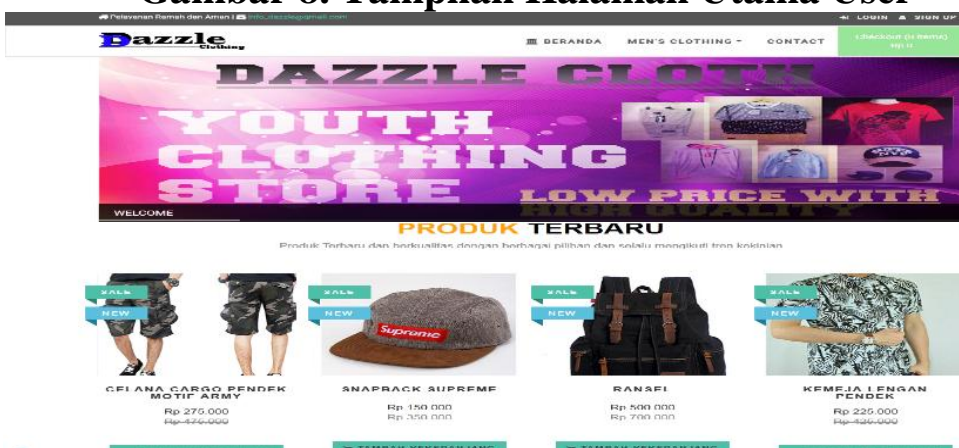

Sumber : Hasil Dokumentasi Website (2018)

\section{Halaman Menu Men's Clothing}

Tampilan pada halaman menu men's clothing menampilkan macam-macam kategori produk yang ditawarkan dazzle store. Seperti yang ditunjukkan pada gambar 9.

\section{Gambar 9. Tampilan Menu Men's Clothing}

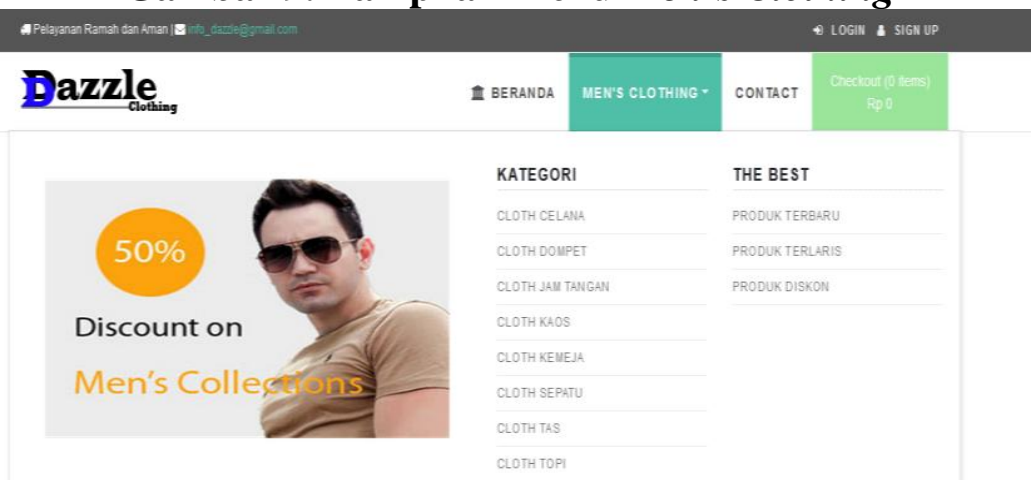

Sumber : Hasil Dokumentasi Website (2018)

\section{Halaman Kategori Produk}

Tampilan ini berisi beberapa jenis kategori produk yang memudahkan customer untuk mencari produk yang diinginkan sesuai kategori yang diinginkan. Seperti yang ditunjukkan pada gambar 10 .

\section{Gambar 10. Tampilan Kategori Produk}

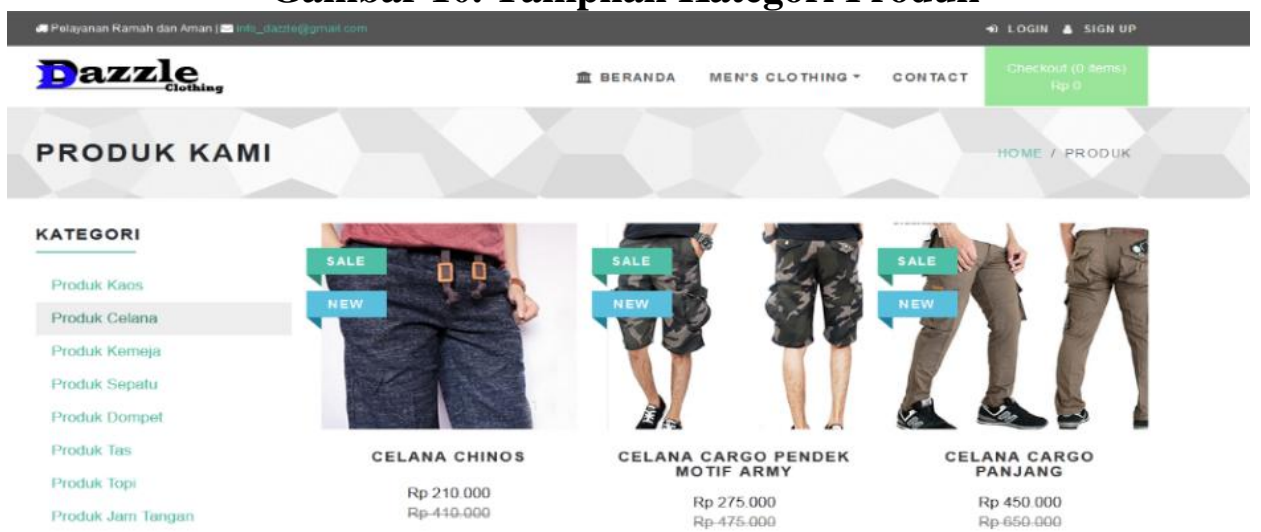

Sumber : Hasil Dokumentasi Website (2018) 


\section{Halaman Register/Login User}

Pada saat user (customer) akan melakukan pembelian maka user non-member wajib registrasi terlebih dahulu dan apabila sudah menjadi user member maka wajib memasukan username dan password di halaman login yang bertujuan untuk melakukan pembelian. Seperti yang ditunjukkan pada gambar 11 berikut ini.

\section{Gambar 11. Halaman Register/Login User}

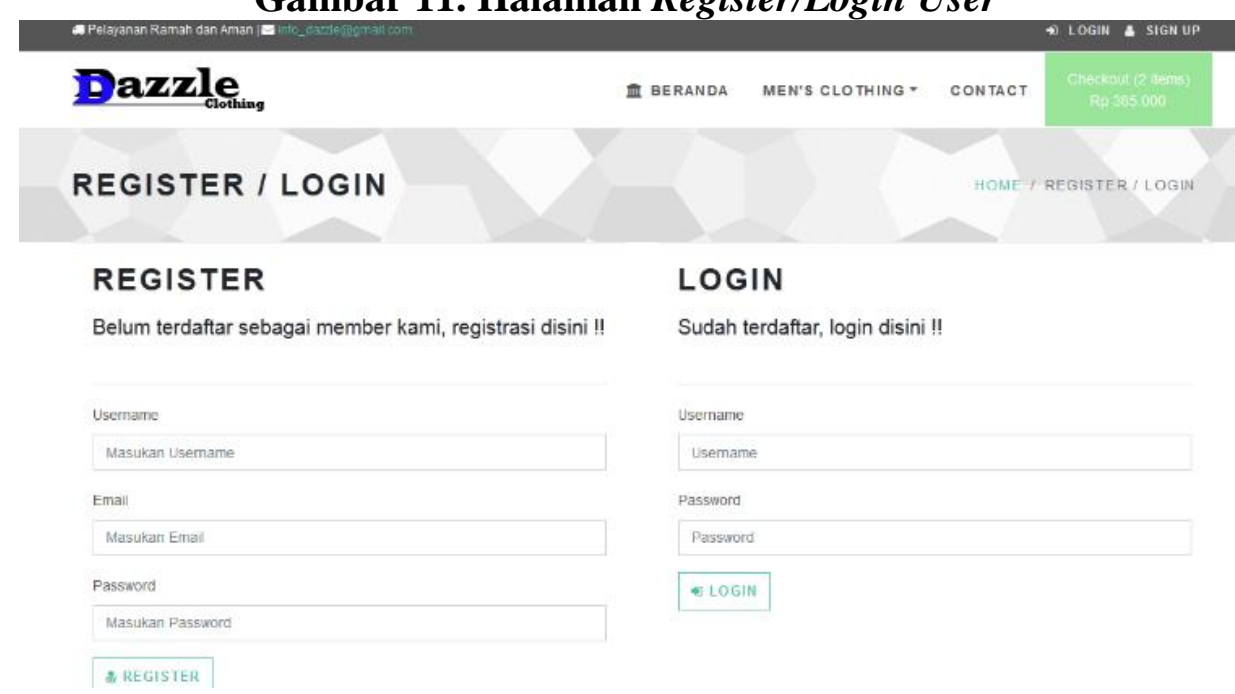

Sumber : Hasil Dokumentasi Website (2018)

\section{Halaman Proses Pembayaran}

Tampilan pada halaman proses pembayaran menampilkan produk yang akan dibeli serta ada total pembayaran yang harus dibayar sesuai prosedur yang ada. Seperti yang ditunjukkan pada gambar 12 berikut ini.

\section{Gambar 12. Halaman Proses Pembayaran}

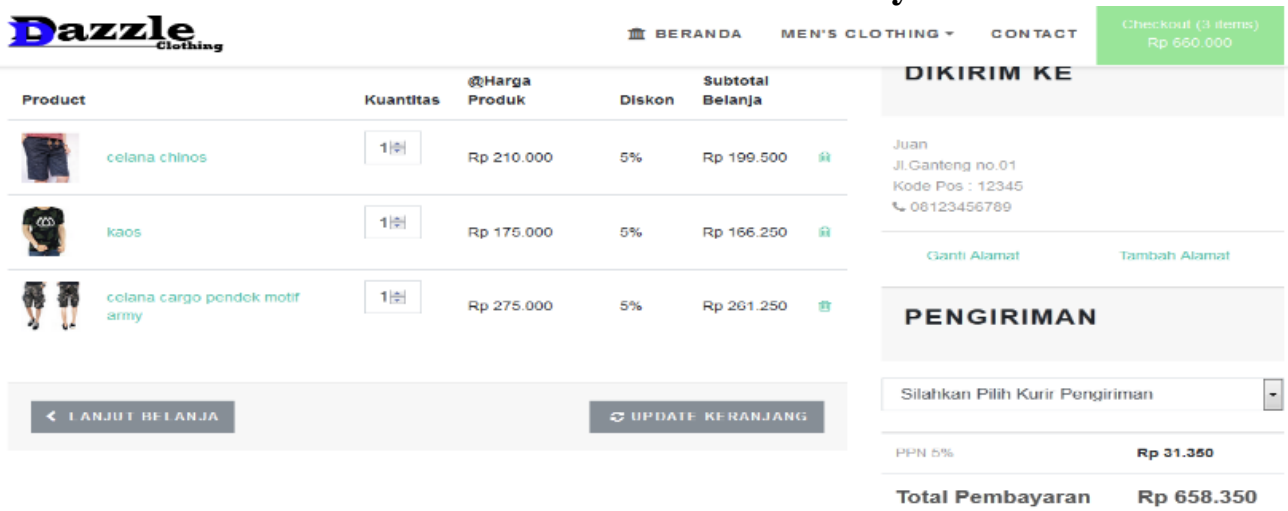

Sumber : Hasil Dokumentasi Website (2018) 


\section{Pengujian Sistem}

\section{Pengujian Black Box}

Pengujian black box bertujuan untuk mengetahui hasil pengujian pada setiap fitur yang ada pada sistem informasi penjualan dan pemesanan Dazzle Store, seperti tabel 1 berikut:

Tabel 1. Pengujian Black Box

\begin{tabular}{|c|c|c|c|}
\hline Menu & Input & Output & Kesimpulan \\
\hline Login & $\begin{array}{l}\text { Memasukkan Username } \\
\text { dan Password yang benar }\end{array}$ & $\begin{array}{l}\text { Menampilkan Halaman } \\
\text { home }\end{array}$ & Sesuai \\
\hline Dashboard & Klik menu Dashboard & $\begin{array}{l}\text { Menampilkan halaman } \\
\text { grafik penjualan }\end{array}$ & Sesuai \\
\hline Produk & Klik menu produk & $\begin{array}{l}\text { Menampilkan halaman } \\
\text { kategori produk \& kelola } \\
\text { produk }\end{array}$ & Sesuai \\
\hline Transaksi & Klik menu transaksi & $\begin{array}{l}\text { Menampilkan halaman } \\
\text { pembayaran \& pengiriman }\end{array}$ & Sesuai \\
\hline Testimoni & Klik menu testimoni & $\begin{array}{l}\text { Menampilkan hasil } \\
\text { testimony yang customer } \\
\text { berikan }\end{array}$ & Sesuai \\
\hline Beranda & Klik menu beranda & $\begin{array}{l}\text { Menampilkan produk } \\
\text { terbaru }\end{array}$ & Sesuai \\
\hline $\begin{array}{l}\text { Men's } \\
\text { Cloting }\end{array}$ & Klik menu men's cloting & $\begin{array}{l}\text { Menampilkan kategori } \\
\text { produk yang tersedia }\end{array}$ & Sesuai \\
\hline Contact & Klik menu contact & $\begin{array}{l}\text { Mengirimkan apabila ada } \\
\text { pesan yang perlu dikirim } \\
\text { ke Dazzle Store }\end{array}$ & Sesuai \\
\hline Logout & $\begin{array}{l}\text { Klik menu logout untuk } \\
\text { keluar dari sistem }\end{array}$ & $\begin{array}{l}\text { Keluar dari sistem dan } \\
\text { menampilkan halaman } \\
\text { login }\end{array}$ & Sesuai \\
\hline
\end{tabular}

Sumber : Hasil Pengujian Black Box (2018)

\section{KESIMPULAN DAN SARAN \\ Kesimpulan}

Berdasarkan dari hasil penelitian yang telah dilakukan, maka dapat diambil kesimpulan bahwa sistem ini dapat membantu admin dalam mempromosikan produk kemasyarakat lebih luas lagi dan dapat mengelola data lebih cepat dan mudah. Hasil dari sistem informasi penjualan dan pemesanan Dazzle Store berbasis website tersebut akan mempermudah customer dalam pembelian produk yang jauh berada dari lokasi Dazzle Store.

\section{Saran}

Berdasarkan dari hasil penelitian, berikut saran untuk penelitian selanjutnya dengan memperbaiki tampilan dari sistem penjualan agar lebih menarik banyak kustomer. 


\section{DAFTAR PUSTAKA}

Pratama, Putu Agus Eka. 2014. Sistem Informasi dan Implementasinya. Bandung: Informatika Bandung.

Pratama, Putu Agus Eka. 2015. E-Commerce, E-Business dan Mobile Commerce. Bandung: Informatika Bandung.

Yuhefizar. 2013. Cara Mudah \& Murah Membangun \& Mengelola Website. Yogyakarta: GRAHA ILMU. 